\title{
Selected metabolites profiling of Orthosiphon stamineus Benth leaves extracts combined with chemometrics analysis and correlation with biological activities
}

Noor Hafizoh Saidan', Mohd Shahrul Ridzuan Hamil ${ }^{1}$, Abdul Hakeem Memon', Maha Mansour Abdelbari', Mohammad Razak Hamdan², Khamsah Suryati Mohd ${ }^{3}$, Amin Malik Shah Abdul Majid ${ }^{4}$ and Zhari Ismail ${ }^{*}$

\begin{abstract}
Background: Studies on selected metabolites profiling of Orthosiphon stamineus extracts using chromatographic and spectroscopic techniques combined with chemometric tools have not been fully elucidated. Thus present study was performed to profile selected metabolites in O. stamineus leaves extracts using HPLC and FTIR combined with chemometric tools and correlated with biological activities.

Methods: Five different extracts were prepared using three methods; maceration, soxhlet and reflux. The extracts were analyzed using UV-Vis, HPLC and FTIR techniques. Analysis of selected primary and secondary metabolites was also evaluated. The antioxidant and cytotoxic activities of the extracts were evaluated. Chemometric tools were employed to classify the extracts based on HPLC analysis and FTIR fingerprints.

Results: The ethanolic extract using maceration characterized high content of phenolics and flavonoids, (rosmarinic acid and eupatorin) with high antioxidant activity. Ethanolic (50 \%) and methanolic extracts using soxhlet showed high proteins and glycosaponins. Water extracts using reflux and maceration showed high polysaccharides.

Methanolic extract (50\%) using soxhlet and methanolic extract using maceration showed strong cytotoxic effect against MCF7 and HCT116 cell lines, respectively. Antioxidant and cytotoxic activities showed significant correlation with selected primary and secondary metabolites. HPLC fingerprints combined with chemometrics showed the extracts have been clustered based on selected major peaks profile. FTIR fingerprints combined with chemometrics showed that the extracts have been clustered based on protein and polysaccharide contents.

Conclusion: Ten different extracts of $\mathrm{O}$. stamineus have showed significant differences in the content of selected primary and secondary metabolites as well as the biological activities. Chemometric tools were able to classify and discriminate the distinctive features of extracts thus can be correlated with the biological activities.
\end{abstract}

Keywords: Metabolites, Orthosiphon stamineus, Lamiacea, HPLC, FTIR, Chemometrics tools, PCA, HCA

\footnotetext{
*Correspondence: zhari@usm.my

'Department of Pharmaceutical Chemistry, School of Pharmaceutical

Sciences, Universiti Sains Malaysia, Minden 11800, Pulau Pinang, Malaysia

Full list of author information is available at the end of the article
}

(c) 2015 Saidan et al. Open Access This article is distributed under the terms of the Creative Commons Attribution 4.0 International License (http://creativecommons.org/licenses/by/4.0/, which permits unrestricted use, distribution, and reproduction in any medium, provided you give appropriate credit to the original author(s) and the source, provide a link to the Creative Commons license, and indicate if changes were made. The Creative Commons Public Domain Dedication waiver (http://creativecommons.org/publicdomain/zero/1.0/) applies to the data made available in this article, unless otherwise stated. 


\section{Background}

Orthosiphon stamineus (Cat's whiskers) is a popular medicinal herb in Southeast Asia and currently cultivated in Malaysia. This herb has gained great interests due to the wide range of pharmacological effects including antioxidant activity [1] and anti-angiogenesis [2]. Based on the great potential of this herb, it has been commercialized for pharmaceutical purposes in Malaysia [3]. Previous phytochemical studies reported that O. stamineus leaves contain high contents of phenolic compounds including lipophilic flavones, flavonol glycosides, caffeic acid derivatives such as rosmarinic acid, 2,3-dicaffeoyltartaric acid [4] and other compounds such as diterpenes, triterpenes including betulinic, ursolic, oleanolic acids and $\beta$ sitosterol [5].

Previous study also showed the occurrence of primary metabolites (proteins, polysaccharides and saponins) in freeze and spray dried methanol extract (50 \%) [2]. Sufficient research work has been done on the analysis of $O$. stamineus $[1,4,6]$. A comparative study of selected metabolites profiling in the different extracts using chromatographic and spectroscopic techniques combined with chemometric tools has not been reported. Previously, a sensor technique combined with chemometric tools (PCA, LDA, HCA and SOM) have been reported for the dried leaves of O. stamineus $[3,7,8]$.

FTIR and HPLC fingerprints of phytochemicals using chromatographic and spectroscopic techniques, may provide valuable information about qualitative and quantitative analysis of medicinal herb in which pattern recognition can be achieved using chemometric tools including PCA and HCA [9]. Therefore, the aim of this study is to profile selected primary and secondary metabolites in different extracts of $O$. stamineus leaves to correlate the profiles with biological activities using HPLC and FTIR combined with chemometric tools (PCA and HCA) for quality control.

\section{Methods}

\section{Preparation of raw material}

Orthosiphon stamineus plant was cultivated and propagated under controlled conditions in a joint venture project of USM-UNIMAP at Titi Tinggi, Perlis, Malaysia. Taxonomic authentication was performed by Mr. Shanmugan A/C Vellosamy (Taxonomist). A voucher specimen (no. 11009) was deposited at the Herbarium, School of Biological Sciences, Universiti Sains Malaysia. The leaves were cut, dried in oven at $40{ }^{\circ} \mathrm{C}$ until fully dried and were ground to powder. Powdered leaves were kept in tight container at $25^{\circ} \mathrm{C}$ [6].

\section{Chemicals and reagents}

Methanol and ethanol (analytical grade), acetonitrile and formic acid (HPLC grade) were purchased from Merck,
Petaling Jaya, (Malaysia). 2,2-diphenyl-1-picrylhydrazyl, quercetin, gallic acid, aluminium chloride, bovine serum albumin, copper sulphate, folin-ciocalteu's reagent, anthrone, sodium carbonate and potassium tartrate were purchased from Sigma-Aldrich, (Germany). The reference compounds rosmarinic acid, 3'-hydroxy-5,6,7,4' tetramethoxyflavone, sinensetin and eupatorin were purchased from ChromaDex, (USA). Deionised water for HPLC was prepared using ultra pure water purifier system Thermo Scientific, (USA). The reverse phase Acclaim Polar Advantage II C18 column $(3 \mu \mathrm{m}, 3 \times 150 \mathrm{~mm})$ was purchased from Dionex, Thermo scientific, (USA). 3-(4,5-dimethylthiazol-2-yl)-2,5-diphenyl tetrazolium bromide, potassium chloride, potassium dihydrogen phosphate, dimethyl sulfoxide and sodium chloride were purchased from Sigma-Aldrich, (USA). Disodium hydrogen phosphate was purchased from Fluka, (Switzerland).

\section{Preparation of extracts}

Three types of extraction techniques; soxhlet, maceration and reflux were used. For soxhlet, dried powdered leaves (250 g) was extracted with methanol, ethanol, methanol (50\%) and ethanol (50\%) in triplicate at $50{ }^{\circ} \mathrm{C}$ for $48 \mathrm{~h}$. For water extraction, reflux and maceration techniques were used. The ratio of raw material to solvent was 1:10. For maceration, dried powdered leaves (250 g) was extracted with methanol, ethanol, methanol (50\%), ethanol (50\%) and water in triplicate at $25{ }^{\circ} \mathrm{C}$ for $72 \mathrm{~h}$. The extracts were concentrated using rotary evaporator at $60{ }^{\circ} \mathrm{C}$.

\section{UV-Visible spectra and calculation of extraction factor} UV-Vis spectra were recorded at 600-200 $\mathrm{nm}$ for ten different extracts using UV-visible spectrophotometer (Perkin Elmer Lambda 45, USA). Briefly, each crude extract $(1 \mathrm{mg}$ ) was dissolved in $1 \mathrm{~mL}$ of respective extraction solvent. The stock solutions were diluted 10 folds to become $100 \mu \mathrm{g} / \mathrm{mL}$ in methanol (50 \%) which was also used as blank. The yield of the extraction in different solvents was calculated using extraction factor (EF) of bioactive molecules from each extract, considering the absorption values $\left(A_{\max }\right)$ recorded for each $\lambda_{\max }$, multiplied with the dilution factor $(\mathrm{d})$. The following formula was used for the calculation of EF:

$$
\mathrm{EF}=\mathrm{A}\left(\lambda_{\max }\right) \times \mathrm{d}
$$

The results were expressed as mean values of three replicates per extracts [9]. 


\section{Determination of selected primary and secondary metabolites}

\section{Determination of total phenolic contents}

The total phenolic contents of different leaves extracts were determined using folin-ciocalteau's method [10] with slight modification. Briefly, for a total of $1 \mathrm{~mL}$ of mixture; $10 \mu \mathrm{L}$ of each extract $(1 \mathrm{mg} / \mathrm{mL})$ was mixed separately in test tube with of folin-ciocalteau's reagent $(50 \mu \mathrm{L})$ followed by the addition of distilled water $(790 \mu \mathrm{L})$. Each mixture was kept at $25{ }^{\circ} \mathrm{C}$ for $10 \mathrm{~min}$ before adding $20 \% \mathrm{Na}_{2} \mathrm{CO}_{3}$ solution $(150 \mu \mathrm{L})$. The samples were incubated at $25{ }^{\circ} \mathrm{C}$ for $1 \mathrm{~h}$ and the absorbance was measured at $\lambda_{\max } 765 \mathrm{~nm}$ against blank without extract. The same procedure was repeated for the standard solution of gallic acid and the calibration line was constructed using a standard curve range from 0.049$400 \mu \mathrm{g} / \mathrm{mL}$ of gallic acid. Total phenolics content were expressed as mg of gallic acid equivalents/g of dry extract (mg GAE/g).

\section{Determination of total flavonoid contents}

The total flavonoid contents of different extracts were determined using aluminium chloride colorimetric method previously reported [11] with. Briefly, quercetin (2 mg) was dissolved in methanol $(5 \mathrm{~mL})$ and seriel ten folds dilutions were prepared with methanol. For a total of $1 \mathrm{~mL}$ solution, $100 \mu \mathrm{L}$ of each crude extract $(2 \mathrm{mg} / \mathrm{mL})$ was mixed separately with $10 \% \mathrm{AlCl}_{3}(20 \mu \mathrm{L}), 1 \mathrm{M}$ of sodium acetate $(20 \mu \mathrm{l})$, methanol $(300 \mu \mathrm{L})$ and water $(560 \mu \mathrm{L})$. The samples were kept at at $25^{\circ} \mathrm{C}$ for $30 \mathrm{~min}$ and the absorbance was measured at $\lambda_{\max } 415 \mathrm{~nm}$ against blank. The standard curve for total flavonoids was obtained using quercetin standard solution from 0.049-400 $\mu \mathrm{g} / \mathrm{mL}$. Total flavonoid contents were expressed as $\mathrm{mg}$ of quercetin equivalents/g of dry extract (mg QE/g).

\section{Determination of total polysaccharide contents}

Total polysaccharide contents in different extracts were measured according to the previous method [12] with slight modification using glucose as standard. Briefly, each crude extract $(10 \mathrm{mg})$ was mixed with $1 \mathrm{~mL}$ of warm ethanol (80\%), vortexed and sonicated for $10 \mathrm{~min}$. The mixtures were then centrifuged at $2700 \mathrm{rpm}$ for $10 \mathrm{~min}$ and the supernatants were discarded. This washing step was repeated for 3 to 5 times. To the precipitate, $10 \mathrm{~mL}$ of $\mathrm{HCl}(1.1 \%)$ was added and the mixtures were heated in a water bath at $60{ }^{\circ} \mathrm{C}$ for $5 \mathrm{~min}$ to dissolve the precipitates. At the end, $5 \mathrm{~mL}$ of $\mathrm{HCl}(1.1 \%)$ and distilled water was added. In separate test tube each mixture $(100 \mu \mathrm{L})$ was pipetted and volume was made up to $1 \mathrm{~mL}$ with distilled water. A standard curve was obtained using glucose as follows; stock solution of glucose $(1 \mathrm{mg} / \mathrm{mL})$ was prepared in distilled water. A series of working standards from $20-100 \mu \mathrm{g} / \mathrm{mL}$ was prepared. Anthrone reagent $(0.2 \%)$ in $\mathrm{H}_{2} \mathrm{SO}_{4}(4 \mathrm{~mL})$ was added separately in each working standard and sample solution. The reaction mixtures were then heated for $8 \mathrm{~min}$ using heating water bath at $60{ }^{\circ} \mathrm{C}$ and kept at $25{ }^{\circ} \mathrm{C}$ to be cooled. The absorbance of mixtures was measured at $\lambda_{\max } 630 \mathrm{~nm}$ using distilled water as blank. Calibration curve $(20-100 \mu \mathrm{g} / \mathrm{mL})$ of glucose was plotted by measuring the absorbance versus concentration. Total amount of polysaccharide contents in each sample was calculated using calibration curve and result was presented in term of $\%$ of total polysaccharides.

\section{Determination of total glycosaponin contents}

Determination of total glycosaponin contents in each extract was evaluated using the gravimetric [2] method with slight modification. Each crude extract (1 g) was refluxed at $60{ }^{\circ} \mathrm{C}$ three times separately using methanol $(50 \mathrm{~mL})$ for $30 \mathrm{~min}$. The mixtures were filtered and concentrated to $10 \mathrm{~mL}$ using rotary evaporator. The concentrated solution was added dropwise in cold acetone $(50 \mathrm{~mL})$ in order to precipitate glycosaponins. Centrifudge was used to fasten precipitation process at $4{ }^{\circ} \mathrm{C}$ at $8000 \mathrm{rpm}$ for $10 \mathrm{~min}$. The precipitates were separated from excess acetone. The precipitate was then dried in the oven at $100{ }^{\circ} \mathrm{C}$ to constant weight. Means of three experiments were collected and the total saponins estimation was expressed in term of \% of total glycosaponins $\pm \operatorname{SD}(n=3)$.

\section{Determination of total protein contents}

The estimation of total protein contents for each crude extract was performed as described previously [13] with slight modification. Freshly prepared an analytical reagent was used in the assay where solution A consisted of sodium carbonate $(2 \% \mathrm{w} / \mathrm{v})$ mixed with sodium hydroxide $(0.1 \mathrm{M})$ and solution $\mathrm{B}$ was copper sulphate $(1.56 \% \mathrm{w} / \mathrm{v})$ added with potassium sodium tartarate $(2.37 \% \mathrm{w} / \mathrm{v})$. Briefly, solution A $(100 \mathrm{~mL})$ was mixed with solution $B(2 \mathrm{~mL})$ to prepare the analytical reagent. Bovine serum albumin (BSA) $(1 \mathrm{mg} / \mathrm{mL})$ was prepared as standard stock solution. Each crude extract (100 mg) was mixed with distilled water $(10 \mathrm{~mL})$ and vortexed shortly. Each mixture was centrifuged for $10 \mathrm{~min}$ at $2700 \mathrm{rpm}$ before supernatant $(0.1 \mathrm{~mL})$ was withdrawn and transferred to separate test tube and made up to final volume with distilled water $(1 \mathrm{~mL})$. Then, the analytical reagent $(3 \mathrm{~mL})$ was added in each test tube and mixed well; the reaction mixture was incubated for $10 \mathrm{~min}$ at $25{ }^{\circ} \mathrm{C}$. Following the incubation, the folinciocalteu's reagent $(200 \mu \mathrm{L})$ was added and each mixture was further incubated at $25^{\circ} \mathrm{C}$ for another $30 \mathrm{~min}$. The absorbance of each extract was determined at $\lambda_{\max }$ $600 \mathrm{~nm}$ againts a blank having all the reagents except 
the crude extract. BSA $(50-250 \mu \mathrm{g} / \mathrm{mL})$ was used as a standard to obtain calibration curve. The estimation of total protein contents of each crudeextract was calculated. Means of three experiments were collected and the total protein estimation was expressed as \% of total protein $\pm \operatorname{SD}(n=3)$.

\section{Antioxidant assays DPPH radical-scavenging activity assay}

DPPH radical scavenging activity of each crude extract was determined by previous method [14] with some modification. Briefly, each crude extract $(1 \mathrm{mg} / \mathrm{mL})$ was dissolved in methanol (50\%). Each sample $(100 \mu \mathrm{L})$ was added to $100 \mu \mathrm{L}$ methanolic DPPH $(200 \mu \mathrm{mol} / \mathrm{L})$ and incubated at $25{ }^{\circ} \mathrm{C}$ for $30 \mathrm{~min}$ in the dark. Ascorbic acid, quercetin and rosmarinic acid (0.39-100 ug/mL) were used as reference standards and the calibration curves were obtained. The amount of remaining DPPH was determined at $\lambda_{\max } 517 \mathrm{~nm}$. The results were expressed as $\%$ inhibition activity.

\section{Feric reducing antioxidant power (FRAP) assay}

Total antioxidant activity by FRAP assay for each crude extract was determined using previous method [15] with slight modification. Briefly, the stock solution of acetate buffer; (300 mM, pH 3.6), 2,4,6-tris (2-pyridyl)-S-triazine (TPTZ) solution, (10 mM TPTZ in $40 \mathrm{mM} / \mathrm{L} \mathrm{HCl})$ and aqueos ferric chloride $(20 \mathrm{mM})$ solution was prepared. From these stock solutions, acetate buffer $(25 \mathrm{~mL})$ was mixed with TPTZ $(2.5 \mathrm{~mL})$ and $\mathrm{FeCl}_{3}: 6 \mathrm{H}_{2} \mathrm{O}(2.5 \mathrm{~mL})$ to make a fresh working solution. Each crude extract $(1 \mathrm{mg} / \mathrm{mL})$ was dissolved separately in methanol and labelled as respective stock solutions. From each crude extract stock solution (200 uL) was added in $1.5 \mathrm{~mL}$ of freshly prepared FRAP reagent (working solution), stirred and incubated for $5 \mathrm{~min}$ in dark condition at $25^{\circ} \mathrm{C}$. The absorbance for each mixture was measured at $\lambda_{\max }$ $593 \mathrm{~nm}$ using FRAP working solution as blank. A calibration curve of ascorbic acid $(0.195-50 \mu \mathrm{g} / \mathrm{mL})$ was used as reference. The relative activity of each crude extract was also compared with rosmarinic acid beacause this compound is abundant in each crude extract. The result $(n=3)$ was expressed as $\mathrm{mg}$ of ascorbic acid or rosmarinic acid equivalents/g of dry extract (mg AAE or RA/g).

\section{Cytotoxic study}

Cytotoxic study of each crude extract was determined using two cancer cell lines including breast cancer (MCF7) and colon cancer (HCT116) cell lines according to the previous methods [16] with minor modification. The assay plates were observed using micro-plate reader (Hitachi U-2000, Japan) at $\lambda_{\max } 570 \mathrm{~nm}$ absorbance and DMSO (1\%) was used as negative control.

\section{Instrumentation and chromatographic condition}

The chromatographic conditions were already validated by [6]. Briefly, using HPLC system (Agilent 1260 Infinity, USA), the chromatographic analysis was carried out using a reverse phase C18 column (Aclaim Polar Advantage II, USA). The diode array detector (DAD) was used at $320 \mathrm{~nm}$ at $40{ }^{\circ} \mathrm{C}$. The gradient elution was used with the mobile phase A ( $0.1 \%$ formic acid) and B (acetonitrile) with flowrate $(1 \mathrm{~mL} / \mathrm{min})$, injection volume $(5 \mu \mathrm{L})$ with 18 min run time.

\section{Preparation of standard solutions}

The marker compounds including rosmarinic acid (RA), 3'-hydroxy-5,6,7,4' -tetramethoxyflavone (TMF), sinensetin (SIN) and eupatorin (EUP) were used to quantify and standardized various crude extracts of O. stamineus leaves. Briefly, the stock solution of each standard (1 $\mathrm{mg} / \mathrm{mL}$ ) was prepared in methanol (50 \%). The working solution $(0.48-250 \mu \mathrm{g} / \mathrm{mL})$ of each standard were prepared from stock solution for obtaining the calibration curve.

\section{Preparation of sample solutions for quantification}

The quantification of selected four marker compounds was performed using validated HPLC method [6]. Briefly, each crude extract $(10 \mathrm{mg})$ was dissolved in $2 \mathrm{~mL}$ of methanol (50\%), sonicated for $10 \mathrm{~min}$ and filtered with $0.45 \mu \mathrm{m}$ membrane filters and analysed by HPLC technique.

\section{Attenuated Total Reflection Fourier Transform Infrared (ATR-FTIR) spectroscopy}

The Fourier transform infrared spectra (FTIR) of each crude extract was recorded in the region from 4000 to $600 \mathrm{~cm}^{-1}$ and 16 scans were accumulated for each spectra using attenuated total reflection (ATR) device (Nicolet iS10, Thermo Scientific, USA). The spectral data was processed using Omnic software (Thermo Scientific, USA). The IR measurement was made at a resolution of $4 \mathrm{~cm}^{-1}$. The ATR diamond was carefully cleaned with ethanol between measurements and dried before applying new sample.

\section{Exploratory data}

The correlation coefficients between antioxidant and cytotoxicity assays with selected metabolites profile including total phenolic, flavonoid, polysaccharide, protein and glycosaponin contents were calculated using SPSS Statistics 17.0. All data were represented as mean \pm SD $(n=3)$.

\section{Data processing for chemometric analysis}

For HPLC, all chromatograms were corrected for baseline and retention time shifted. The peak area over 
weight $(\mathrm{PA} / \mathrm{W})$ of each peak was calculated using Microsoft excel before transfer to PCA. For FTIR data, the baselines of spectra were corrected using Omnic software (Thermo Scientific, USA). In this study, natural clusters of HPLC and FTIR data was analyzed by PCA using The Unscrambler X (CAMO, Trondheim, Norway) software. Hierarchical clustering analysis (HCA) classification was employed on PCA data to discriminate the metabolites of each crude extract.

\section{Results and discussion}

\section{UV-Vis fingerprints and Extraction factor (EF)}

The selection of extraction technique plays an important role for fingerprint analysis of $O$. stamineus extracts. Three different techniques of extraction were performed in present study, namely soxhlet, maceration at $25{ }^{\circ} \mathrm{C}$ and reflux. Five different solvents have been chosen including methanol, methanol (50\%), ethanol, ethanol (50 \%) and water. From this study, comparative UV-Vis profile of each crude extract was recorded in order to have an integrated image of the differences between solvent type and concentration of bioactive constituents extracted.

The extraction factor (EF) mean values for phenolic acid derivatives at $270-290 \mathrm{~nm}$ and flavonoids between $317-340 \mathrm{~nm}$ for each crude extract were calculated and presented in Table 1. From the result it has been observed that EF in ethanol extract using maceration technique produced highest concentration of phenolic acid and flavonoid derivatives as compared to other crude extracts while water extract using maceration showed the lowest concentration. This result revealed that solvent and extraction techniques play an important role in extracting the phenolic compounds especially phenolic acid and flavonoid derivatives which also contributed their role in therapeutic effects [17].

\section{Estimation of total primary and secondary metabolites}

Quantitative analysis of selected primary and secondary metabolites including flavonoids, phenolics, polysaccharides, proteins and glycosaponins was carried out for ten different crude extracts (Table 2). It was observed that different extraction techniques gave different amount of selected metabolites. The phenolic contents (TPC) were ranged from 108.2 $\pm 0.9-467.1 \pm 1.5 \mathrm{mg} / \mathrm{g}$ GAE where macerated ethanolic extract showed the maximum TPC, in contrast with macerated water extract which shown the lowest TPC. This data is in agreement with UV-Vis profile as mention earlier. The variation in TPC values might due to the polarity of the solvents used to extract polyphenols from plant materials. The total flavonoid content (TFC) for different extracts ranged from $69.0 \pm 0.1-174.3 \pm 0.2 \mathrm{mg} / \mathrm{g}$ QE. The result showed that, macerated ethanolic extract consisted the highest
Table 1 The absorption maxima $\left(\lambda_{\max }\right)$ in different extracts of $O$. stamineus leaves from UV-Vis and the value of extraction factor (EF)

\begin{tabular}{|c|c|c|}
\hline Extracts & wavelength $\left(\lambda_{\max }\right)$ & Extraction Factor $(\mathrm{EF}) \pm \mathrm{SD}$ \\
\hline \multirow[t]{2}{*}{${ }^{*}$ meoh-s } & 329 & $136.29 \pm 0.10$ \\
\hline & 286 & $122.85 \pm 0.56$ \\
\hline \multirow[t]{2}{*}{${ }^{*} \mathrm{mw}-\mathrm{s}$} & 328 & $142.49 \pm 0.05$ \\
\hline & 283 & $158.25 \pm 0.07$ \\
\hline \multirow[t]{2}{*}{ * etoh-s } & 329 & $107.29 \pm 0.02$ \\
\hline & 283 & $119.66 \pm 0.16$ \\
\hline \multirow[t]{2}{*}{ * ew-s } & 331 & $108.61 \pm 0.01$ \\
\hline & 284 & $110.79 \pm 0.08$ \\
\hline \multirow[t]{2}{*}{ * water-r } & 329 & $135.38 \pm 0.04$ \\
\hline & 284 & $136.77 \pm 0.02$ \\
\hline \multirow[t]{2}{*}{ * meoh-m } & 331 & $125.02 \pm 0.02$ \\
\hline & 285 & $113.96 \pm 0.01$ \\
\hline \multirow[t]{2}{*}{${ }^{*} \mathrm{mw}-\mathrm{m}$} & 328 & $161.88 \pm 0.01$ \\
\hline & 283 & $186.98 \pm 0.05$ \\
\hline \multirow[t]{2}{*}{ * etoh-m } & 332 & $264.83 \pm 0.02$ \\
\hline & 286 & $228.31 \pm 0.05$ \\
\hline \multirow[t]{2}{*}{ * ew-m } & 329 & $167.21 \pm 0.24$ \\
\hline & 286 & $135.01 \pm 0.05$ \\
\hline * water-m & 279 & $104.17 \pm 0.01$ \\
\hline
\end{tabular}

${ }^{*}$ meoh-s = methanol soxhlet; $\mathrm{mw}-\mathrm{s}=$ methanol:water (1:1) soxhlet; etoh-s = ethanol soxhlet; ew- $s=$ ethanol:water (1:1) soxhlet; water- $r=$ water reflux; meoh- $\mathrm{m}=$ methanol maceration; $\mathrm{mw}-\mathrm{m}=$ methanol:water $(1: 1)$ maceration; etoh- $\mathrm{m}=$ ethanol maceration; ew-m = ethanol:water (1:1) maceration; water- $\mathrm{m}=$ water maceration

total flavonoid, phenolic contents and antioxidant activity. For total protein analysis (TPA), Lowry's method was used to estimate TPA in different crude extracts of $O$. stamineus leaves. The assay is a colorimetric assay based on cupric ions and follin-ciocalteau's reagent for phenolics [13].

TPA for different crude extracts was ranged from $10.1 \pm 0.2-38.9 \pm 0.3 \% \mathrm{w} / \mathrm{w}$ of dry extract where ethanolic (50\%) extract using soxhlet showed the highest contents of TPA while ethanolic (50 \%) macerated extract showed lowest TPA contents. Methanol extract using soxhlet showed the highest content of total glycosaponin with $30.4 \pm 0.6 \% \mathrm{w} / \mathrm{w}$ of dry extract while water extract using maceration showed the lowest contents of total glycosaponins with $4.0 \pm 0.1 \% \mathrm{w} / \mathrm{w}$ of dry crude extract. In contrast, water extracts using reflux and maceration showed high contents of total polysaccharides with $23.7 \pm 0.0 \%$ and $25.5 \pm 0.1 \%$ w/w of dry crude extracts, respectively. The result showed that the polysaccharide contents in this plant are water soluble and the extraction technique with controlled temperature preserved the primary metabolites in these extracts. Among selected five phyto-constituents, total polysaccharide contents 
Table 2 Determination of selected primary and secondary metabolites, antioxidant activities and anti-prolferative activities from different extracts of 0 . stamineus leaves

\begin{tabular}{|c|c|c|c|c|c|c|c|c|c|}
\hline \multirow[t]{2}{*}{${ }^{*} \mathrm{~A}$} & \multirow[t]{2}{*}{$* 1$} & \multirow[t]{2}{*}{$* 2$} & \multirow[t]{2}{*}{$* 3$} & \multirow[t]{2}{*}{$* 4$} & \multirow[t]{2}{*}{$* 5$} & \multirow[t]{2}{*}{$* 6$} & \multirow[t]{2}{*}{ * 7} & \multicolumn{2}{|l|}{$* 8$} \\
\hline & & & & & & & & ${ }^{*} 8 \mathrm{a}$ & $* 8 b$ \\
\hline${ }^{*} \mathrm{~A} 1$ & $358.2 \pm 3.9$ & $158.6 \pm 0.1$ & $29.9 \pm 0.0$ & $30.4 \pm 0.6$ & $0.4 \pm 0.0$ & $90.3 \pm 0.8$ & $47.7 \pm 0.1$ & $51.5 \pm 4.0$ & $39.5 \pm 3.3$ \\
\hline${ }^{*} \mathrm{~A} 2$ & $383.4 \pm 1.2$ & $148.6 \pm 0.3$ & $31.2 \pm 0.2$ & $26.2 \pm 0.2$ & $13.5 \pm 0.0$ & $86.0 \pm 0.3$ & $49.0 \pm 0.2$ & $54.3 \pm 2.4$ & $36.4 \pm 4.1$ \\
\hline${ }^{*} \mathrm{~A} 3$ & $289.3 \pm 1.0$ & $112.2 \pm 0.4$ & $10.9 \pm 0.3$ & $18.3 \pm 0.2$ & $20.9 \pm 0.1$ & $84.4 \pm 0.3$ & $31.0 \pm 0.1$ & $48.7 \pm 0.1$ & $26.3 \pm 0.6$ \\
\hline${ }^{*} \mathrm{~A} 4$ & $339.6 \pm 1.3$ & $148.0 \pm 0.2$ & $38.9 \pm 0.3$ & $27.5 \pm 0.6$ & $14.0 \pm 0.0$ & $87.4 \pm 0.2$ & $36.4 \pm 0.3$ & $46.6 \pm 3.3$ & $29.3 \pm 3.5$ \\
\hline * A5 & $246.2 \pm 2.0$ & $74.9 \pm 0.1$ & $22.0 \pm 0.2$ & $20.0 \pm 0.2$ & $23.7 \pm 0.0$ & $74.5 \pm 0.2$ & $43.8 \pm 0.2$ & $20.2 \pm 1.3$ & $32.8 \pm 1.9$ \\
\hline * A6 & $296.7 \pm 1.0$ & $110.1 \pm 0.2$ & $16.3 \pm 0.2$ & $21.9 \pm 0.8$ & $3.6 \pm 0.1$ & $88.7 \pm 0.1$ & $40.3 \pm 0.1$ & $49.5 \pm 1.5$ & $43.7 \pm 1.2$ \\
\hline * A7 & $308.5 \pm 1.0$ & $94.2 \pm 0.1$ & $21.8 \pm 0.2$ & $19.1 \pm 0.1$ & $0.65 \pm 0.01$ & $88.5 \pm 0.2$ & $45.7 \pm 0.2$ & $44.1 \pm 3.3$ & $36.7 \pm 1.3$ \\
\hline * A8 & $467.1 \pm 1.5$ & $174.3 \pm 0.2$ & $11.6 \pm 1.4$ & $19.6 \pm 0.1$ & $21.7 \pm 0.1$ & $94.2 \pm 0.2$ & $48.7 \pm 0.3$ & $54.2 \pm 1.8$ & $24.6 \pm 1.9$ \\
\hline *A9 & $251.2 \pm 3.6$ & $113.1 \pm 0.2$ & $10.1 \pm 0.2$ & $16.7 \pm 0.1$ & $1.01 \pm 0.0$ & $73.2 \pm 0.1$ & $21.4 \pm 0.4$ & $44.0 \pm 3.3$ & $31.3 \pm 1.7$ \\
\hline${ }^{*} \mathrm{~A} 10$ & $108.2 \pm 0.9$ & $69.0 \pm 0.1$ & $23.8 \pm 0.1$ & $4.0 \pm 0.1$ & $25.5 \pm 0.1$ & $50.3 \pm 0.2$ & $20.0 \pm 0.4$ & $8.5 \pm 0.6$ & $40.4 \pm 3.0$ \\
\hline
\end{tabular}

${ }^{*} \mathrm{~A}=$ Extracts; $\mathrm{A} 1=$ meoh-s; $\mathrm{A} 2=\mathrm{mw}-\mathrm{s} ; \mathrm{A} 3=$ etoh-s; $\mathrm{A} 4=\mathrm{ew}-\mathrm{s} ; \mathrm{A} 5=$ water-r; $\mathrm{A} 6=$ meoh-m; $\mathrm{A} 7=\mathrm{mw}-\mathrm{m} ; \mathrm{A} 8=\mathrm{etoh}-\mathrm{m} ; \mathrm{A} 9=\mathrm{ew}-\mathrm{m} ; \mathrm{A} 10=\mathrm{water}-\mathrm{m} ; 1=\mathrm{TPC}(\mathrm{mg} / \mathrm{g}$ $\mathrm{GAE}) \pm \mathrm{SD}, 2=\mathrm{TFC}(\mathrm{mg} / \mathrm{g}$ QE) $\pm \mathrm{SD}, 3=$ Total protein $(\%) \pm \mathrm{SD}, 4=$ Total saponins $(\%), 5=$ Total saccharide $(\%) \pm \mathrm{SD}, 6=\mathrm{DPPH}(\%$ inhibition) $\pm \mathrm{SD}, 7=\mathrm{FRAP}(\mathrm{mg} / \mathrm{g}$ $\mathrm{AAE}) \pm \mathrm{SD}, 8=\mathrm{MTT}$ (\% inhibition) $\pm \mathrm{SD}, 8 \mathrm{a}=\mathrm{MCF} 7 \pm \mathrm{SD}$, and $8 \mathrm{~b}=\mathrm{HCT} 116 \pm \mathrm{SD}$

were found in least amount in all samples except in water crude extracts. The correlation among selected five phytoconstituents was calculated using Pearson's correlation as shown in Table 3. All selected phyto-constituents are positively correlated except the polysaccharides which are negatively correlated to the rest of the phyto-constituents indicating a decrease in its value along the increase in the other phyto-constituents.

\section{Antioxidant assay}

Antioxidant properties of ten different crude extracts were analyzed using DPPH and FRAP assays. The antioxidant activity of different crude extracts is shown in Table 2 where water extracts exhibited low antioxidant activity with both antioxidant methods. This could be due to low contents of total phenolic and flavonoid in these crude extracts.

From the correlation study (Table 3), DPPH showed significant correlation with total phenolics, flavonoids and saponins while FRAP showed significant correlation with total phenolics and saponins. This result also corroborate with previous result where it showed $\mathrm{DPPH}$ and FRAP assays have significant correlation with total phenolic contents [15]. Previous study had also reported that apart from phenolic compounds, other compounds such as ursolic, oleanolic and betulinic acids present in O. stamineus might also contributed to antioxidant activity [1]. This data also indicated that the antioxidant activitiy of different crude extracts varied due to polarities of different solvents.

\section{Cytotoxic activity}

This study evaluated the cytotoxic activity of ten different crude extracts using two cancer cell lines including MCF7 and HCT116 (Table 2). From this result, the activity varied between different crude extracts using different extraction techniques. Various extracts $(100 \mu \mathrm{g} / \mathrm{mL})$ possessed cytotoxic activity on MCF7 and HCT116 ranged from $8.5 \pm 0.6-54.26 \pm 2.4 \%$ and $24.6 \pm 1.9 \%-43.7 \pm 1.2 \%$ inhibition, respectively. Methanolic extract (50 \%) using

Table 3 Correlation among the selected phytoconstituents and activities observed in different extracts of O. stamineus leaves

\begin{tabular}{llllllllll}
\hline Variables & Phenolic & Flavonoids & Protein & Saponins & Saccharides & DPPH & FRAP & MCF7 & HCT \\
\hline Phenolic & 1.00 & $0.89^{* *}$ & 0.07 & $0.73^{*}$ & -0.14 & $0.90^{* *}$ & $0.78^{* *}$ & $0.85^{* *}$ & -0.44 \\
Flavonoids & $0.89^{* *}$ & 1.00 & 0.20 & $0.69^{*}$ & -0.15 & $0.73^{*}$ & $0.71^{*}$ & $0.81^{* *}$ & -0.35 \\
Protein & 0.07 & 0.20 & 1.00 & 0.46 & -0.07 & 0.36 & 0.28 & -0.05 & 0.29 \\
Saponins & $0.73^{*}$ & $0.69^{*}$ & 0.46 & 1.00 & -0.44 & $0.87^{* *}$ & $0.70^{*}$ & $0.73^{*}$ & -0.06 \\
Sacharides & -0.14 & -0.15 & -0.07 & -0.44 & 1.00 & -0.46 & -0.12 & $-0.76^{*}$ & 0.45 \\
DPPH & $0.90^{* *}$ & $0.73^{*}$ & 0.36 & $0.87^{* *}$ & -0.46 & 1.00 & $0.76^{*}$ & $0.89^{* *}$ & -0.26 \\
FRAP & $0.78^{* *}$ & $0.71^{*}$ & 0.28 & $0.70^{*}$ & -0.12 & $0.76^{*}$ & 1.00 & 0.52 & 0.01 \\
MCF7 & $0.85^{* *}$ & $0.81^{* *}$ & -0.05 & $0.73^{*}$ & $-0.76^{*}$ & $0.89^{* *}$ & 0.52 & 1.00 & -0.25 \\
HCT116 & -0.44 & -0.35 & 0.29 & -0.06 & -0.45 & -0.26 & 0.01 & -0.25 & 1.00 \\
\hline
\end{tabular}

Significant levels were showed as ${ }^{*}=p<0.05 ;{ }^{* *}=p<0.01$ 
soxhlet showed the strongest cytotoxic effect against MCF7 with $54.3 \pm 2.4 \%$ inhibition while water exract using maceration showed the weakest activity with $8.5 \pm 0.6 \%$ inhibition.

From Table 3, this result indicated that the cytotoxic activity is related to the antioxidant properties of crude extracts. MCF7 showed significant correlation with DPPH $(0.89, p<0.01)$ while HCT116 showed negative correlation with DPPH $(-0.26, p>0.05)$ and non-significant with FRAP assay $(0.01, p>0.05)$. MCF7 also showed significant correlation with total saponins $(0.73, p<0.05)$, phenolics $(0.85, p<0.01)$ and flavonoid contents $(0.81, p<0.01)$ and negatively correlated with total polysaccharides $(-0.76, p<0.05)$. Previous study reported that antioxidant activity contributed significantly to the cytotoxic activity of O. stamineus extract [18].

\section{HPLC profile and quantitative analysis}

HPLC analysis was carried out to evaluate the quality of $O$. stamineus extracts based on selected marker compounds (RA, TMF, SIN and EUP). In order to standardize the HPLC profile, crude extracts were analyzed using an established method [6]. Figure 1 shows a typical HPLC fingerprints and the overlapped chromatograms of ten different crude extracts using maceration, soxhlet and reflux techniques. Seven common peaks were selected as characteristic peaks. Out of seven common peaks, only four peaks were quantified based on the comparison of retention time with pure standards and DAD profile. Accordingly, compounds labelled 2, 3, 4 and 5 were identified as RA, TMF, SIN and EUP, respectively.

From Fig. 1c, among two techniques, ethanolic extract from maceration showed high contents of RA and EUP with $3.15 \% \mathrm{w} / \mathrm{w}$ and $1.46 \% \mathrm{w} / \mathrm{w}$, respectively. While water extract (reflux) showed high contents of RA with $2.89 \% \mathrm{w} / \mathrm{w}$ followed by ethanolic and methanolic extracts (soxhlet) with $2.57 \%$ and $1.87 \%$, respectively. This result shows a good agreement with UV-Vis profile as mention earlier where ethanolic extract from maceration showed high absorption at 270-290 nm (phenolic acids) and 317-340 $\mathrm{nm}$ (flavonoids). The values of TMF and SIN were in the range of $0.17-0.27 \%$ and $0.18 \%-$ $0.40 \% \mathrm{w} / \mathrm{w}$, respectively. The result also showed that the contents of each marker compounds in different crude extracts were significantly different.

\section{Chemometrics analysis on HPLC dataset}

In order to evaluate the differences of these characteristic peaks, PCA was performed on the basis of the contents of quantified compounds (RA, TMF, SIN and EUP) and PA/W values of remaining peaks in HPLC fingerprints using multivariate statistical (The Unscrambler X CAMO, Trondheim, Norway) software. Data was exported to Microsoft Excel to form a two dimensional matrix (ten samples versus seven variables) which was then exported to statistical (The Unscrambler X, CAMO, Trondheim, Norway) software for PCA and HCA anaysis.

The scores plot obtained from PCA is shown in Fig. 2a. It is shown that the extracts mainly distributed into four groups; group I-IV. Two components, PC-1 and PC2 showed accounted of $97 \%$ of total variance. From the scores plot, group I and II were in the positive PC-1 axis while group III and IV were in the negative PC-1 axis. Based on the result, those samples with similar chemical profiles are grouped near to each other while larger distance was observed in samples with different chemical profile. To find the variables that contributed to the significant differences between different extracts, the correlation loading plots of PC-1 and PC-2 were generated (Fig. 2b). From correlation loading plots, the $\mathrm{PC}-1$ loading plot indicated that peak 2 (RA) contributed positively to the positions of extracts in group I and II, whereas peak 5 (EUP) contributed in the position of ethanolic extract (50\%) using maceration in group III at negative PC-1 while water extract using maceration (group IV) was influenced by peak 1 (unknown 1). From Fig. 2b, it also showed that peak 6 (unknown 2) and peak 7 (unknown 3) are located in the inner circle, means they did not influenced the discrimination of ten different crude extracts.

Further, to confirm either peak 3 (TMF) or peak 4 (SIN) was contributing to the discrimination of the crude extracts, the Bi-plot was generated and showed (Fig. 2c). From this, it showed that peak 3 (TMF), peak 4 (SIN), peak 6 (unknown 2) and peak 7 (unknown 3) were closed to the centre of origin. It indicates that they did not have enough structural variations to show discriminating factor for the extracts. In this study, group I containing of ethanolic extract (50\%) using soxhlet has the highest $\mathrm{PA} / \mathrm{W}$ values of peak 2 (RA) followed by water extract using reflux. From group II, ethanolic extract using maceration has the highest contents of peak 2 (RA) followed by methanolic extract using soxhlet and this group has second highest of PA/W values of peak 2 (RA) after group I. From negative PC-1, ethanolic extract $(50 \%)$ using maceration has the highest $\mathrm{PA} / \mathrm{W}$ values of peak 5 (EUP) and negative correlation with peak 2 (RA) while water extract using maceration has the highest $\mathrm{PA} / \mathrm{W}$ values of peak 1 (unknown 1 ) and negative correlation with peak 2 (RA).

According to PC-2 scores, methanolic extract (50\%) using soxhlet has second highest of $\mathrm{PA} / \mathrm{W}$ values of peak 5 (EUP) and peak 2 (RA) and making it's location on the top in scores plot. Taking together, PCA analysis be able to differentiate and classify the extracts based on the content of seven compounds. Peak 2 (RA) appears in 


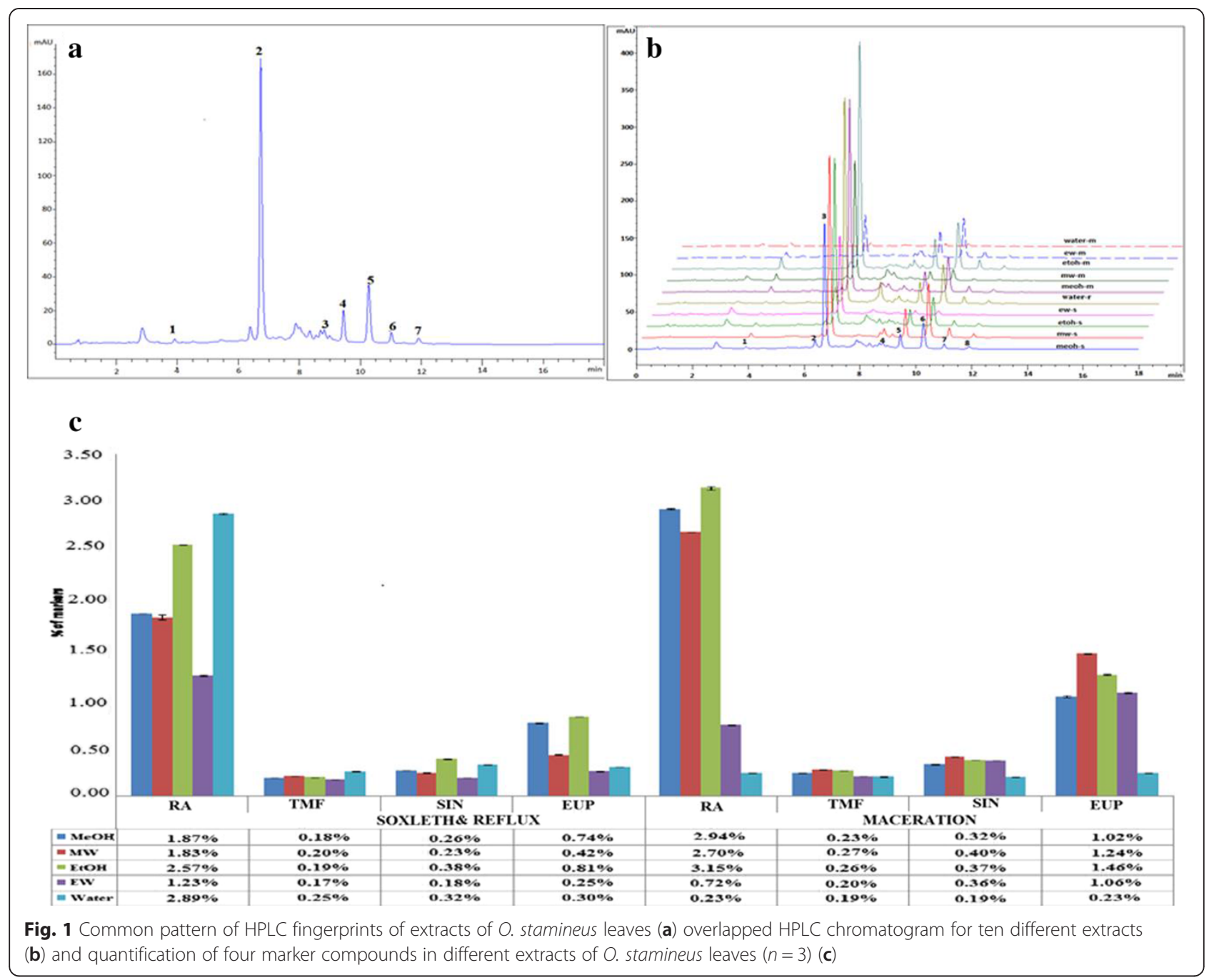

high concentration in all crude extracts and from the loading plot it influences mostly on the separation among different group of samples. Thus, RA also can be used as chemical marker together with SIN in HPLC for quality control of $\mathrm{O}$. stamineus extracts in the future. Currently, only SIN has been used as a marker compound for identification and authentication of O. stamineus extracts.

\section{Hierarchical clustering analysis (HCA) for HPLC fingerprinting}

The HPLC fingerprint pattern from ten different crude extracts are almost similar. It is difficult to identify the similarity or differences between the extracts. So, in order to assess this tendency, hierarchical cluster analysis was employed. The analysis was performed on the PCA data of values of seven characteristic peaks found in different crude extracts of O. stamineus using (The Unscrambler X, CAMO, Trondheim, Norway) software.
The Ward's hierarchical clustering method with Euclidean distance was used in this study. The dendogram of HCA are shown in Fig. 2d which shows that the extracts were divided into two main clusters; I and II, which further divided into four subgroups; A-D. This cluster was in a good agreement with PCA pattern as discussed earlier. The samples with similar chemical profiles were clustered into the same subgroups. Group I and II were clustered as in Fig. 2d due to the major influenced by peak 2 (RA). Group I containing ethanolic extract $(50 \%)$ using maceration was less in PA/W values of peak 2 (RA) but high in PA/W of peak 5 (EUP) and water extract using maceration was also less in peak 2 (RA) but high in peak 1 (unknown 1), so the relative distance between these two extracts is far from each other. Group II containing other extracts were highly in PA/W values of peak 2 (RA) and less PA/W values of peak 1 (unknown 1) and peak 5 (EUP). It was found that different solvents were used in the extraction gave different chemical profiles and clustered separately. Extracts with 


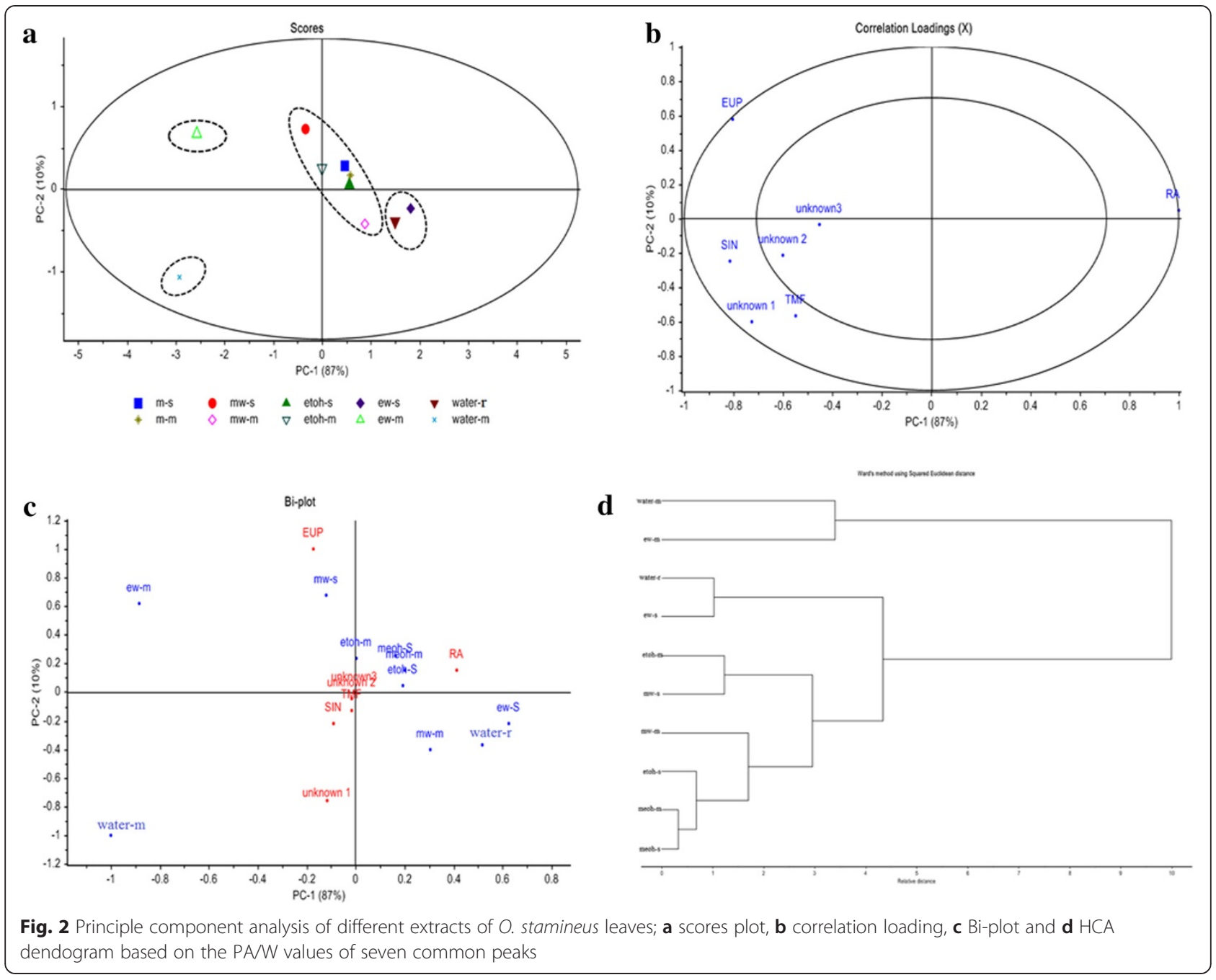

similar PA/W values were classified in the same group and major peaks (RA) play an important role than small peaks for classification and discrimination of extracts.

\section{FTIR fingerprints for different extracts of $O$. stamineus}

In this study, FTIR spectra of each crude extract was recorded in IR region from $4000-600 \mathrm{~cm}^{-1}$ with 16 scans. The FTIR spectra was used to identify the functional groups in ten different crude extracts. Figure $3 a$ and $b$ present the FTIR spectra of ten different crude extracts extracted from three different techniques; maceration, soxhlet and reflux, respectively. In all crude extracts, the broad peak at $3550-3200 \mathrm{~cm}^{-1}$ are due to the intermolecular of hydrogen bonding. The vibration area of $2900-2800 \mathrm{~cm}^{-1}$ are assigned to the asymmetric and symmetric stretching vibration of methylene groups $\left(\mathrm{CH}_{2}\right.$ and $\left.\mathrm{CH}_{3}\right)$, methoxy derivatives, $\mathrm{C}-\mathrm{H}$ (aldehydes) including cis double bonds [9]. No peak at these region was observed for water extracts.
From Fig. 3a and b, the main differences between the extracts were in the region between $1800-800 \mathrm{~cm}^{-1}$ known as fingerprint region [19] which can give more information on the mixture of primary and secondary metabolites. The peak at $1760-1600 \mathrm{~cm}^{-1}$ are assigned as $\mathrm{N}-\mathrm{H}$ bending vibration for amino acid [9], $\mathrm{C}=\mathrm{O}$ stretching in carbonyl compounds which may be characterized by the presence of high contents of terpenoid and flavonoid in the complex mixtures of extracts. With respect to the phenolic compounds, the absorption peak at the region $1650-1450 \mathrm{~cm}^{-1}$ is due to aromatic ring stretching and the peak at the range of $1420-1330 \mathrm{~cm}^{-1}$ is due to $\mathrm{O}-\mathrm{H}$ in plane deformation absorption bands [20]. The most intense peak at $\sim 1047 \mathrm{~cm}^{-1}$ appear in all extracts suggested that the extracts were highly in flavonoid contenst or might be due to the compounds containing alcohol groups through the stretching vibrations of $=\mathrm{C}-\mathrm{O}$ $\mathrm{C}, \mathrm{C}-\mathrm{C}$ or bending vibration of $\mathrm{C}-\mathrm{OH}$ bonds [21].

Peak at $1680-1540 \mathrm{~cm}^{-1}$ was appeared in all extracts and assigned as proteins region and the typical fingerprint 

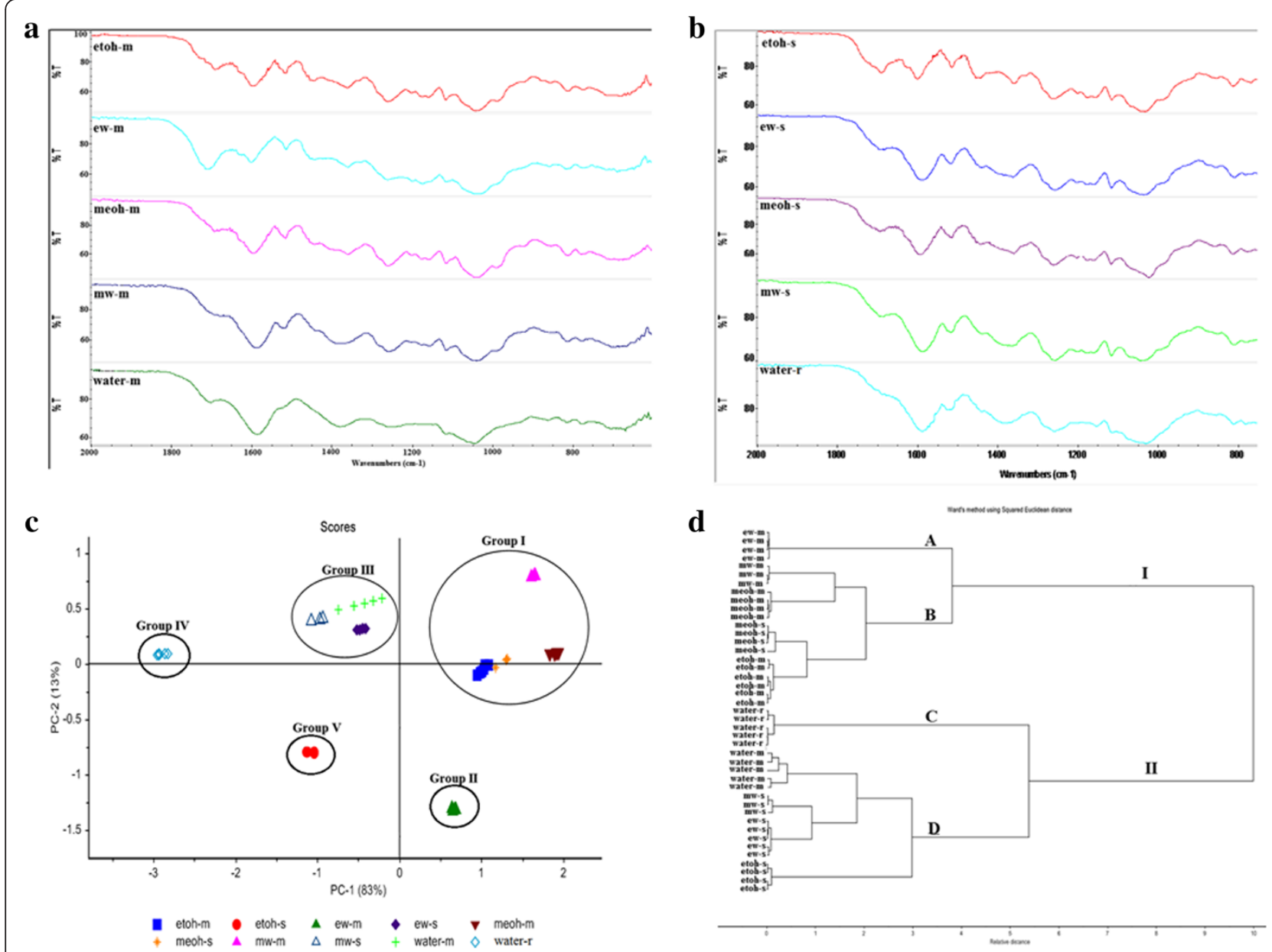

d

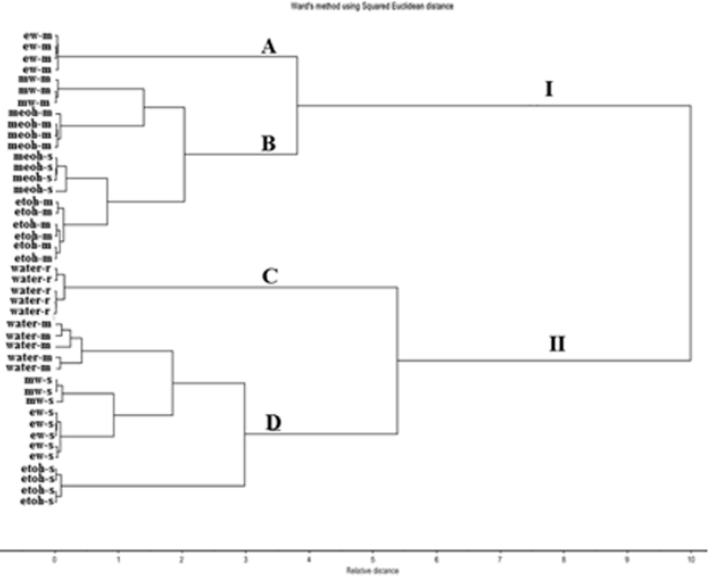

Fig. 3 FTIR spectra of different extracts of $O$. stamineus leaves using; a maceration $\mathbf{b}$ soxleth and reflux (water) with principal component analysis c scores plot and $\mathbf{d}$ HCA dendogram

regions of carbohydrate was observed at the region of $1200-900 \mathrm{~cm}^{-1}$ [22]. Fig. 3a and b showed the intensity of peaks in protein regions were higher in all extracts. As showed in Table 2, the order of total protein contents in extracts using soxleth: ethanolic $(50 \%)>$ methanolic $(50 \%)>\mathrm{MeOH}>$ Water $($ reflux $)>$ $\mathrm{EtOH}$. This same pattern was also found in the extracts using maceration technique. Comparing the intensity of this region $\left(1680-1540 \mathrm{~cm}^{-1}\right)$ in ethanolic $(50 \%)$ extract using soxhlet and ethanolic extract (50\%) using maceration, the intensity was higher in ethanolic extract (50\%) using soxhlet showed that the total protein contents in this extract is higher than ethanolic extract $(50 \%)$ using maceration. Meanwhile, the intensity of this region are lower in ethanolic extract using soxhlet and maceration, showed that the total protein contents are low in these extracts. The presence of protein in the extracts was further confirmed by the peak region at $1550-1504 \mathrm{~cm}^{-1}$ indicating the presence of $\mathrm{N}-\mathrm{H}$ bending vibration of primary amines and the presence of strong peak at $1515 \mathrm{~cm}^{-1}$ indicated for secondary aromatic amines. The absorption peak at region $1275-1200 \mathrm{~cm}^{-1}$ was associated to the assymetrical C-O-C stretching.

\section{Chemometric analysis on FTIR dataset}

The PCA was performed on the FTIR spectral features between the wavenumber region of $1800-800 \mathrm{~cm}^{-1}$ which is known as fingerprint region [19] using (The Unscrambler X, CAMO) software. Figure $3 \mathrm{a}$ and $\mathrm{b}$, showed that the FTIR fingerprints in all extracts look similar and only intensity of the peaks is different. So, to identify the similarity or diffferences between extracts, the PCA scores plot of ten different extracts were generated (Fig. 3c). The scores plot were generated from comparisons of the two PCs; PC-1 and PC-2 which encounted of $96 \%$ of total variants.

A significant separation was observed in all extracts revealed the differences in chemical composition among them. Therefore, in two principle components, there are able to form a cluster in the two dimensional plot. 
According to the scores plot, there are five different groups; groups I-V. Group I and II were clustered at positive PC-1 axis. Group I and II containing extracts (maceration) except one extract from soxhlet $(\mathrm{MeOH})$ which is in group I while at negative PC-1 axis, group III-V containing extracts from soxhlet except water extract (maceration) which is in group III. It might be due to the chemical profile of the extracts in FTIR spectra is similar. Those samples with similar chemical profiles are near to each other while the larger the distance showed differences in their chemical profiles.

In order to identify the peaks that contributed to the discrimination of extracts, loading plots of PC-1 and PC-2 was generated and it showed that peak at $1275-1200 \mathrm{~cm}^{-1}$ (C-O-C stretching) and 1200-900 $\mathrm{cm}^{-1}$ (carbohydrates) were the main variants for positive and negative PC-1 loading while peak at $1760-1600 \mathrm{~cm}^{-1}$ (amino acids, terpenoids and flavonoids), $1680-1540 \mathrm{~cm}^{-1}$ (proteins) and $1420-1330 \mathrm{~cm}^{-1}$ (O-H ) were contributed for clustering both positive and negative PC-2 loading. High intensity of the peak at $1200-900 \mathrm{~cm}^{-1}$ corresponding to the carbohydrate region compared to other peak indicating that this peak mostly contributed to the discrimination of the extracts in positive and negative $\mathrm{PC}-1$ axis.

Table 2 shows the result of total polysaccharides in ten different crude extracts. All extracts in group I and II showed a lower contents of total polysaccaride while group at negative PC-1 loading showed higher contents of total polysaccharide. For positive and negative PC-2 axis, there are three peaks that influenced the discrimination of the extracts including the region of proteins $\left(1680-1540 \mathrm{~cm}^{-1}\right)$. Extracts in positive PC-2 axis showed high contents of total protein while extracts at negative PC-2 axis showed low contents of protein. From the PCA result, proteins and polysaccharides regions play an important role for the discrimination of the O. stamineus extracts in scores plot. Further research in these region is needed in order to understand the discrimination obtained from PCA.

\section{Hierarchical clustering analysis (HCA) for FTIR fingerprinting}

In order to see the similarities and dissimilarities between FTIR fingerprints of different extracts, the cluster analysis was conducted using (The Unscrambler $\mathrm{X}$, CAMO, Trondheim, Norway) software. The Ward's hierarchical clustering method with Euclidean distance was used in this study. The dendogram of HCA obtained by the PCA on FTIR data are shown Fig. 3d. From these, the extracts were grouped into two major clusters; I and II. Group I was divided into two subgroups; A and B where subgroup A consists of macerated ethanolic extract $(50 \%)$ while subgroup B was further divided into two subgroups which consists of macerated methanolic (50\%), methanolic, ethanolic and methanolic extracts.

Group II was further divided into subgroups C and D, where subgroup $C$ consists of water extract using reflux while subgroup D was further divided into two subgroups that consists of macerated water extract, methanolic (50\%), ethanolic (50\%) and ethanolic extracts using soxhlet. This cluster was in a good agreement with PCA pattern as discussed above. The samples with similar chemical profiles were clustered into the same subgroups. Group I and II were clustered as in Fig. 3d due to the major influenced by total polysaccharide and protein contents. Thus, grouping in HCA of different extracts of O. stamineus confirmed the clustering in PCA scores where group I was clustered in positive PC-1 axis while group II was clustered in negative PC-1 axis.

\section{Conclusions}

To our best knowledge, studies on selected metabolites profiling of $O$. stamineus leaves extracts using chromatographic and spectroscopic techniques combined with chemometrics tools are scanty. So, this is the first report presenting such an elaborate study. Findings from this study can be employed as a template for quality control either in raw materials, extracts or finish products of $O$. stamineus leaves extracts and would be an important tool for selection of potential extracts for further product development study of O. stamineus leaves extracts.

\section{Abbreviations}

DPPH: 2,2-diphenyl-1-picrylhydrazyl; $\left(\mathrm{AlCl}_{3}\right)$ : Aluminium chloride; BSA: Bovine serum albumin; HPLC: High performance liquid chromatograpy; FTIR: Fourier transform infrared spectroscopy; UVNis: Utra-violet visible spectroscopy; RA: rosmarinic acid; TMF: 3'-hydroxy-5,6,7,4'-tetramethoxyflavone; SIN: sinensetin; EUP: eupatorin; MTT: 3-(4,5-dimethylthiazol-2-yl)-2,5-diphenyl tetrazolium bromide; DMSO: Dimethyl sulfoxide; rpm: Revolutions per minute; PBS: Phosphate buffer saline; PCA: Principle component analysis; HCA: Hierarchical clustering analysis; $\mathrm{Na}_{2} \mathrm{CO}_{3}$ : sodium carbonate.

\section{Competing interests}

The authors declare that they have no competing interests.

\section{Authors' contributions}

$\mathrm{NHS}$ and $\mathrm{ZI}$ contributed with the conception of the study including primary and secondary metabolites analysis, HPLC and FTIR analysis. NHS, MMA and AMSAM were responsible for the design and execution of the antioxidant dan cytotoxic assays and the experiments were conducted in the laboratories of AMSAM. NHS, MRH, MSRH and KSM were involved in the chemometric analysis and AHM was contributed in revising this paper. All authors contributed to further writing of the manuscript. All authors read and approved of the final manuscript.

\section{Authors' information}

Not applicable.

\section{Acknowledgements}

The authors would like to acknowledge Universiti Sains Malaysia (USM) for providing the facilities to do the research and funding current project (Grant name: USM-RU-FRGS, 1001/PFARMASI/843114) and Ministry of Science, Technology and Innovation, Malaysia (MOSTI) for giving NHS a scholarship reward. Finally, we would like to thank Mr. Shanmugan A/C Vellosamy from School of Biological Sciences, USM for authentication of plant materials. 


\section{Author details}

${ }^{1}$ Department of Pharmaceutical Chemistry, School of Pharmaceutical Sciences, Universiti Sains Malaysia, Minden 11800, Pulau Pinang, Malaysia. ${ }^{2}$ Centre of Drug Research, School of Pharmaceutical Sciences, Universiti Sains Malaysia, Minden 11800, Pulau Pinang, Malaysia. ${ }^{3}$ School of Agriculture and Biotechnology, Faculty of Bioresources and Food Industry, Universiti Sultan Zainal Abidin, Tembila Campus, 22200 Besut, Terengganu, Malaysia. ${ }^{4}$ Department of Pharmacology, School of Pharmaceutical Sciences, Universiti Sains Malaysia, Minden 11800, Pulau Pinang, Malaysia.

Received: 12 May 2015 Accepted: 28 September 2015

Published online: 07 October 2015

\section{References}

1. Akowuah A, Zhari I, Norhayati I, Sadikun A, Khamsah S. Sinensetin, eupatorin, 3'-hydroxy-5, 6, 7, 4'-tetramethoxyflavone and rosmarinic acid contents and antioxidative effect of Orthosiphon stamineus from Malaysia. Food Chem. 2004;87:559-66.

2. Siddiqui M, Hafizoh S, Zhari I, Sahib H, Helal M, Abdul Majid A. Analysis of Total Proteins, Polysaccharides and Glycosaponins Contents of Orthosiphon stamineus Benth. In Spray and Freeze Dried Methanol: Water(1:1) extract and its Contribution to Cytotoxic and Antiangiogenic Activities. Pharmacognosy Res. 2009;1:320.

3. Zakaria A, Shakaff A, Adom A, Ahmad M, Masnan M, Abdul Aziz A, et al. Improved classification of Orthosiphon stamineus by data fusion of electronic nose and tongue sensors. Sensors (Basel). 2010;10:8782-96.

4. Sumaryono W, Proksch P, Wray V, Witte L, Hartmann T. Qualitative and Quantitative Analysis of the Phenolic Constituents from Orthosiphon aristatus. Planta Med. 1991;57:176-80.

5. Tezuka Y, Stampoulis P, Banskota A, Awale S, Tran K, Saiki I, et al. Constituents of the Vietnamese medicinal plant Orthosiphon stamineus. Chem Pharm Bull (Tokyo). 2000;48:1711-9.

6. Saidan N, Aisha A, Mohd Hamil S, Abdul Malik A, Ismail Z. A novel reverse phase high performance liquid chromatography method for standardization of Orthosiphon stamineus leaf extracts. Pharmacognosy Res. 2015;7:23-31.

7. Sim C, Ahmad M, Zhari I, Othman A, Mohd Noor N, Zaihidee E. Chemometric Classification of Herb- Orthosiphon stamineus According to Its Geographical Origin Using Virtual Chemical Sensor Based Upon Fast GC. Sensors. 2003;3(January):458-71

8. Dharmaraj S, Hossain M, Zhari S, Harn G, Ismail Z. The use of principal component analysis and self-organizing map to monitor inhibition of calcium oxalate crystal growth by Orthosiphon stamineus extract. Chemom Intell Lab Syst. 2006;81:21-8.

9. Zavoi S, Fetea F, Ranga F, Pop M, Baciu A, Socaciu C. Comparative Fingerprint and Extraction Yield of Medicinal Herb Phenolics with Hepatoprotective Potential, as Determined by UV-Vis and FT-MIR Spectroscopy. Not Bot Horti Agrobo. 2004;39:82-9.

10. Folin O, Ciocalteu V. Tyrosine and Tryptophane in Proteins. J Biol Chem. 1927;73:627-50.

11. Chang C, Yang M, Wen H, Chern J. Estimation of total flavonoid content in propolis by two complementary colometric methods. J Food Drug Anal. 2002;10:178-82.

12. Adams D, Emerson M. Variations in Starch and total polysaccharide content of Pinus Ponderosa needles with fluride fumigation. Plant Physiol. 1961;36:261.

13. Lowry OH, Rosebrough NJ, Farr L, Randall RJ. Protein Measurement with the Folin Phenol Reagent. J Biol Chem. 1951:193:265-75.

14. Wang K, Yang C, Zhang Y. Phenolic antioxidants from Chinese toon (fresh young leaves and shoots of Toona sinensis). Food Chem. 2007;101:365-71.

15. Benzie I, Szeto $Y$. The ferric reducing ability of plasma (FRAP) as a measure of "antioxidant power": the FRAP assay. Anal Biochem. 1996;239:70-6.

16. Al-Suede F, Farsi E. Marked antitumor activity of cat's whiskers tea (Orthosiphon stamineus) extract in orthotopic model of human colon tumor in nude mice. J Biochem Tech. 2014:3:170-6.

17. Hollman P, Katan M. Dietary Flavonoids: Intake, Health Effects and Bioavailability. Food Chem Toxicol. 1999:37:937-42

18. Al-Suede F, Khadeer Ahamed M, Abdul Majid A, Baharetha H, Hassan L, Kadir M, et al. Optimization of Cat's Whiskers Tea (Orthosiphon stamineus) Using Supercritical Carbon Dioxide and Selective Chemotherapeutic Potential against Prostate Cancer Cells. Evid Based Complement Alternat Med. 2014;2014:396016.
19. Hussain K, Ismail Z, Sadikun A, Ibrahim P. Evaluation of extracts of Piper sarmentosum for accelerated stability by metabolomic fingerprint profiling Introduction. Pharmacognosy Res. 2009;1:185-91.

20. Vázquez G, Fontenla E, Freire M, González-Álvrez J, Antorrena G. Antioxidant activity and phenolic content of chestnut (Castanea sativa) shell and eucalyptus (Eucalyptus globulus) bark extracts. Ind Crops Prod. 2008:28:279-85.

21. Sinelli N, Spinardi A, Di Egidio V, Mignani I, Casiraghi E. Evaluation of quality and nutraceutical content of blueberries (Vaccinium corymbosum L.) by near and mid-infrared spectroscopy. Postharvest Biol Technol. 2008;50:31-6.

22. Uarrota V, Moresco R, Coelho B, Nunes E, Peruch L, Neubert E, et al. Metabolomics combined with chemometric tools (PCA, HCA, PLS-DA and SVM) for screening cassava (Manihot esculenta Crantz) roots during postharvest physiological deterioration. Food Chem. 2014;161:67-78.

\section{Submit your next manuscript to BioMed Central and take full advantage of:}

- Convenient online submission

- Thorough peer review

- No space constraints or color figure charges

- Immediate publication on acceptance

- Inclusion in PubMed, CAS, Scopus and Google Scholar

- Research which is freely available for redistribution 